\section{Questión}

Periodismo / Comunicación ISSN 1669-6581
- Av. $44 \mathrm{~N}^{\circ} 676,1^{\circ}$ piso

CP 1900 - La Plata - Argentina

www.perio.unlp.edu.ar/question

La gestión de riesgo desde el territorio

Sebastián Claramunt - Pablo Diotto

https://doi.org/10.24215/16696581e358

\title{
La gestión de riesgo desde el territorio
}

Notas sobre pandemia en sociedades arrasadas por el neoliberalismo

\section{Risk management from the territory}

Notes on a pandemic in societies devastated by neoliberalism

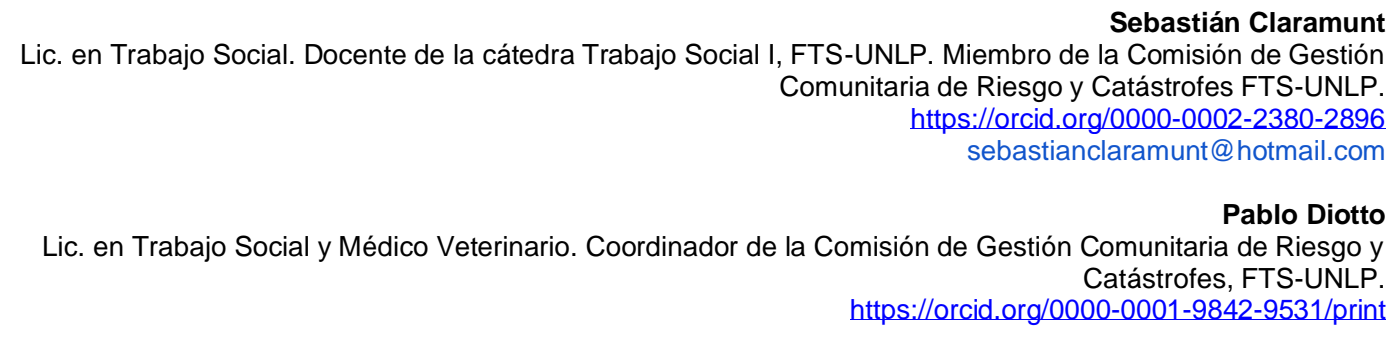

\section{Palabras Claves}

Gestión - Riesgo - Territorio - Pandemia

\section{Key Words}

Management - Risk - Territory - Pandemic

"Frente a las enfermedades que genera la miseria, frente a la tristeza la angustia y el infortunio social de los pueblos, los microbios, como causas de enfermedad, son unas pobres causas" Ramón Carrillo ¿A qué escenarios llega la pandemia mundial del coronavirus? a una Argentina de 4 años (20162020) de caída libre en la economía productiva, un recetario de medidas de desguace del Estado 
y de vaciamiento de los sistemas de protección social. Ni un solo indicador acompaña a la distribución de la riqueza en este periodo en favor de las mayorías populares. Desde la perspectiva de la Gestión de Riesgo y en especial con un enfoque territorial, nos pone en el necesario ejercicio de contextualizar e historizar a las comunidades donde se interviene. Estos ejercicios nos van a llevar a una serie de reflexiones que intentan pensar más allá del análisis de la epidemia, como situación que pone en riesgo a una sociedad, que se encontraba muy lejos de estar en armonía hasta su aparición.

La mirada de los fenómenos como la pandemia del COVID-19, desde la perspectiva de la Gestión de Riesgo y en especial con un enfoque territorial, nos pone en el necesario ejercicio de contextualizar e historizar a las comunidades donde se interviene. Estos ejercicios nos van a llevar a una serie de reflexiones que intentan pensar más allá del análisis de la epidemia, como situación que pone en riesgo a una sociedad, que se encontraba muy lejos de estar en armonía hasta su aparición.

También pone luz sobre los procesos sucedidos previamente, las decisiones que se han venido tomando sobre un escenario en disputa, desde el origen mismo de la historia: el Estado, los modelos que ponen en pugna la visión e intervención en este periodo del país, pero fundamentalmente en los periodos donde el virus no era una amenaza y las decisiones sobre la vida de nuestros pueblos eran otras.

¿A qué escenarios llega la pandemia mundial del coronavirus? a una Argentina de 4 años (20162020) de caída libre en la economía productiva, un recetario de medidas de desguace del Estado y de vaciamiento de los sistemas de protección social. Ni un solo indicador acompaña a la distribución de la riqueza en este periodo en favor de las mayorías populares. Sin entrar en finas cuentas, la concentración de la riqueza cada vez es mayor a nivel mundial, y en nuestro país cerca del $50 \%$ de lo producido queda en menos de un $20 \%$ de la población. Fuga de capitales, transferencia de divisas a paraísos fiscales, concentración en lo económico, amplias mayorías sumergidas en la pobreza y desocupación, y como novedad histórica: sin la fuerza de las armas, las políticas antipopulares validadas con el voto de las mayorías. En este caso un omnipresente e incansable aparato de poder, que nos mantiene en una situación de presente permanente, donde hasta hace casi un mes, recordémoslo, se lanzaba el plan "Argentina contra el hambre" y era el único hecho que parecía suceder en nuestro país. 


\section{El hambre es un crimen;¿la organización popular también?}

En el periodo del gobierno anterior, la política del Estado fue claramente, una conjunción de decisiones a favor de los grupos concentrados de poder: los empresarios como funcionarios públicos, la desarticulación de los organismos de contralor, el vaciamiento de las políticas públicas como herramienta de soberanía popular, y fundamentalmente la criminalización de la protesta social, con toda la represión institucional (y la no también) puesto al servicio de la defensa de los intereses corporativos. Las policías comunales, provinciales y federales en el mantenimiento del orden interno: parque indoamericano, represión en el Borda entre otros, y fuerzas como gendarmería o prefectura, como grupos de choque de elite. Basta recordar episodios como la ley previsional, el conflicto de tierras en el sur del país, etc. A su vez, la articulación grotesca con un aparato judicial que ejecutó el encarcelamiento de dirigentes territoriales y políticos aun vigentes, como formas de disciplinamiento ejemplarizante: la materialidad sostenida en el tiempo de las sanciones que tienen los que cuestionan o enfrentan colectiva o individualmente al poder.

"Hemos atravesado un periodo donde a demasiados niños y a demasiada gente se les ha hecho pensar de esta forma: 'itengo un problema, la labor del Estado es resolverlo!'. O ‘tengo un problema, conseguiré un subsidio para resolverlo!'. O 'iNo tengo vivienda, el Estado debe dármela!'. Al hacer eso trasladan sus problemas a la sociedad, y ¿quién es la sociedad? No existe tal cosa. Lo que existe son hombres y mujeres individuales, existen las familias. No hay Estado que pueda hacer nada sino es a través de las personas, y las personas se preocupan primero de sí mismas". Margaret Thatcher 1987

La construcción de sentido, con un fuerte anclaje en los heterogéneos sectores medios, y precisamente, a través de los medios, de un discurso "antipolítico", fragmentado, meritocrático, individualista, que instala un manto de sospecha sobre todo proceso organizativo popular, sobre las organizaciones territoriales y sus dirigentes, sobre las conducciones sindicales y todo proceso que permita desde la propia comunidad organizarse para reclamar la dignidad avasallada permanentemente por el mercado. El modelo cubano de organización social, esta desgastado para el imperio como un paradigma global del mal, el tiempo hizo que los logros de la revolución sean indiscutibles, entonces Venezuela ocupa en Nuestra Latinoamérica ese espacio en esta contemporaneidad: primero Chávez, ahora Maduro. Porque los intentos de organización popular 
se pagan caros, porque todo lo que escape a los modelos de democracias que vayan en más 0 en menos por fuera de los formalismos plesbicitarios son atacados y pretender pensarnos desde otra comunidad posible, para los pueblos Latinoamericanos sigue siendo delito, no hay alternativa posible, es criminal. Así, en nuestro país uno de los casos paradigmáticos es la organización Túpac Amaru y sus dirigentes, que son arrasados, si, literalmente arrasados por un plan sistemático de exterminio: encarcelamiento, destrucción y abandono de las obras realizadas, un bombardeo informativo de destrucción simbólica de todo lo que tenga que ver con la organización. Esa "otredad" que permite constituir sentido de esos otros, que pueden ser sujeto de los más aberrantes crímenes por parte del poder, sin que esto sea repudiable por las mayorías.

Si cada cual es empresario de sí mismo, debe hacerse cargo de sí. Se "responsabiliza" a cada uno, al par que se le quita toda responsabilidad sobre el cuidado de la comunidad. Desaparecen las solidaridades de clase, de grupo o de posición ideológica. El gobierno deviene gobernanza y la acción política se reduce a una guía de mejores prácticas. Lo político se desvanece y su lugar es ocupado por las políticas públicas. Junto con lo político se desvanece el conflicto, en nombre de un consenso negador de cualquier demanda de justicia. De este modo, por vía de la responsabilización de los individuos, se legitima que el Estado deje de atender cuestiones relativas a la salud, la educación, el transporte o el empleo. Enrique Del Percio. La Agonía Neoliberal: Del Emprendedor Exitoso Al Sacrificio Compartido.

\section{Las estrategias desde la Gestión del Riesgo}

Los procesos que amenazan y ponen en riesgo a nuestras comunidades han sido abordados desde distintos lugares del conocimiento y desde diferentes momentos históricos. Particularmente en el momento de las crisis, es donde la intervención planificada toma otra dimensión, por su posicionamiento entre lo territorial y lo institucional. Por eso pensar a la Gestión del Riesgo como campo de acción, desde la dimensión comunitaria, es una práctica que no nos debería ser ajena a nuestra profesión, el Trabajo Social. La definición de la Ley 27.287 del Sistema Nacional para la Gestión Integral del Riesgo y la Protección Civil nos define a la Gestión Integral del Riesgo (GIR) como: "un proceso continuo, multidimensional, interministerial y sistémico de formulación, adopción e implementación de políticas, estrategias, planificación, organización, dirección, ejecución y control, prácticas y acciones orientadas a reducir el riesgo 
de desastres y sus efectos, así como también las consecuencias de las actividades relacionadas con el manejo de las emergencias y/o desastres. Comprende acciones de mitigación, gestión de la emergencia y recuperación "(Art. 2, inc. h).

Conceptos como amenaza, catástrofe, vulnerabilidad y riesgo, cobran nuevo sentido a la luz de los enfoques de complejidad, y re definen nuevos modos de abordaje en cada una de las instancias operacionales que define la GIR como campo problemático y puede entenderse como un conjunto de acciones dirigidas a la reducción del riesgo (prevención y mitigación), así como la atención del desastre (respuesta, rehabilitación y reconstrucción), en el que se le da un papel predominante al primer aspecto.

Diferentes autores (Arito y Jacquet, 2005; Barrantes Castillo, 2011; Herrero Muguruza, 2011; López Nieto y García, 2000), han compartido sus enfoques respecto a las situaciones de emergencia para pensar este tema, poniendo en diálogo los saberes de intervención del Trabajo Social en particular, con las herramientas que las diferentes disciplinas han desarrollado para las situaciones de crisis. Porque necesariamente, los abordajes a realizar en la GIR son transversales a la visión y acción de múltiples disciplinas profesionales y técnicas que operan en el territorio.

Ante esto, las construcciones colectivas serán a través de los diálogos de saberes presentes en los territorios" Es el tiempo histórico para que esto sea posible. En un presente lleno de incertidumbre, el aporte del diálogo de saberes en la construcción de nuevos sentidos es una puerta fundamental a los procesos de transformación" (Arrúa, 2006). Los dispositivos de intervención que se generan en estos escenarios de cambios cotidianos donde los sucesos que están ocurriendo a nivel global, van a impactar en la situación territorial, donde la intervención se configura "como campo problemático en la medida que ella se constituye en el escenario cotidiano donde se objetivan las manifestaciones de la cuestión social y, que reconfiguran el mundo social de los sujetos." (Margarita Rozas,2010) por lo que es imprescindible entonces retomar los saberes comunitarios, vincular, recuperar las historias, los sentires y las vivencias, aportar al fortalecimiento de las organizaciones, para enfrentar también las otras "viejas catástrofes" (salud, educación, trabajo, hábitat entre otras) y su relación con estas "nuevas catástrofes", en el escenario de elaboración de estrategias para la gestión del riesgo.

Desde la formación de profesionales al servicio de los intereses de las mayorías populares, sabemos que al pensar estrategias y abordajes en esta situación de contexto histórico, debemos 
tener un anclaje territorial en las historias, sentires, procesos y significados, y en la trama que los constituye. La irrupción en nuestras vidas de esta pandemia y su impacto político y social, nos refuerza el sentido de construcción desde la Comunidad Organizada, donde avanzando con el Estado y las políticas públicas hacia el pleno ejercicio de los derechos, nos permite alcanzar lo que nos pertenece irrenunciablemente : la dignidad como Pueblo.

\section{Bibliografía}

ARITO, SANDRA y MONICA JACQUET (2005), "EI Trabajo Social en situaciones de emergencia y catástrofe" Espacio Editorial, Universidad Nacional de Entre Ríos.

ARRÚA VANESA, "La producción de conocimiento desde el dialogo de saberes", en Revista Trama, Año 5, 2006

BARRANTES CASTILLO GUSTAVO, MÁRQUEZ REYES RODRIGO (2011) "De la atención del Desastre a la Gestión del Riesgo; una visión desde la Geografía". Revista Geográfica de América Central N47. II Semestre.

BIBLIOTECA DEL CONGRESO DE LA NACIÓN (ARGENTINA).Perón: La comunidad organizada (1949). Incluye la Reforma Constitucional sancionada por la Convención Nacional Constituyente en 1949. 2.a ed. Buenos Aires: Biblioteca del Congreso de la Nación, 2016.

BOLETíN OFICIAL DE LA REPÚBLICA ARGENTINA, LEY 27.287, 20 de Octubre de 2016 Sistema Nacional de Gestión integral del Riesgo y la Protección Civil (SINAGIR)

ITZIAR HERRERO MUGURUZA (2011) "Los Trabajadores sociales en situaciones de crisis, emergencias y catástrofes" Revista Margen № 63, Buenos Aires.

LÓPEZ NIETO Y GARCÍA. (2000) "Intervención de Trabajo Social y Situación de Desastre". Revista de Trabajo Social N2. Universidad Nacional de Colombia.

POLITICA SANITARIA ARGENTINA, Editorial UNLa, Cuadernos del ISCo, Serie Clásicos 2018. 